\title{
Intestinal failure defined by measurements of intestinal energy and wet weight absorption
}

\author{
P B Jeppesen, P B Mortensen
}

\begin{abstract}
Background and aims-Intestinal failure defined by the minimal energy and wet weight absorption required to avoid home parenteral nutrition (HPN) is not well described. Thus the aim of this study was to identify the minimal level of gut function necessary to avoid parenteral support using objective measurements of intestinal function.
\end{abstract}

Methods-Energy (bomb calorimetry) and wet weight absorption were measured during 48 hour balance studies in 45 HPN patients with intestinal failure and in 44 non-HPN borderline patients with a short bowel or malabsorption exceeding $2 \mathrm{MJ} / \mathrm{day}$.

Results-In the non-HPN patients, the lower $5 \%$ confidence interval of the absorption of energy was $84 \%$ of the basal metabolic rate (BMR, the Harris-Benedict equations), equivalent to $4.9 \mathrm{MJ} / \mathrm{day}$. Wet weight absorption was $1.4 \mathrm{~kg} /$ day. The HPN patients absorbed less of either or both. The non-HPN patients absorbed $24-86 \%$ (range) of the energy and $23-95 \%$ of the wet weight. Absorption in the HPN patients ranged from below $0 \%$ (net secretion) in patients with very short bowels to $100 \%$ absorption of an insufficient oral intake in patients with pseudo-obstruction. Non-HPN patients who absorbed less than half of their intake avoided HPN by hyperphagia (200$400 \%$ of BMR equivalent to $10-24 \mathrm{MJ} / \mathrm{day}$, and 3-7 kg/day of wet weight).

Conclusion-Intestinal failure was accurately measured as absorption below $1.4 \mathrm{~kg} / \mathrm{day}$ of wet weight and $84 \%$ of the calculated BMR (depending on weight, sex and age), which is equal to $4.9 \mathrm{MJ} / \mathrm{day}$. Intestinal absorption, expressed as a percentage of intake, did not discriminate between patients with and without intestinal failure, except for patients who absorbed less than $25 \%$ of their intake.

(Gut 2000;46:701-706)

Keywords: absorption; intestinal failure; energy; wet weight; short bowel syndrome

Rigshospitalet, University of Copenhagen

Blegdamsvej 9 DK-2100 Copenhagen,

Denmark

P B Jeppesen

P B Mortensen

Correspondence to:

Dr P B Jeppesen

Accepted for publication 25 November 1999 mal amount necessary to maintain nutrient and fluid balance, frequently termed oral failure, ${ }^{2}$ is seen in patients with pseudoobstruction and dysmotility syndromes. The principal cause of intestinal failure, however, is a reduction in the functioning gut mass, as seen in short bowel syndrome. In individuals with a healthy intestinal mucosa, a small bowel of $50-70 \mathrm{~cm}$ in length provided the colon is intact, or of 100-150 cm in length if resection is accompanied by a colectomy, ${ }^{3-5}$ is required to maintain nutritional integrity and autonomy with enteral feedings and to avoid intestinal failure and dependence on parenteral support. There are, however, exceptions to this rule as intestinal absorptive function rather than length determines the final outcome. Therefore, a functional measure of the intestinal absorptive capacity using bomb calorimetry has been advocated in the management of patients with intestinal insufficiency and failure, ${ }^{6}$ but implementation and use in everyday clinical practice has been protracted.

For the objective measurement of intestinal function, we used a short term procedure designed to obtain a high level of patient compliance. Intestinal absorption was evaluated using bomb calorimetry combined with measurement of dietary and faecal weight. The procedure focused on the ability to distinguish between patients who required and those who did not require $\mathrm{HPN}$, thereby defining the minimal gut function needed to avoid intestinal failure in terms of energy and wet weight absorption.

\section{Materials and methods}

PATIENTS

Two groups of patients were recruited to the study by mail. The first group comprised 58 patients with intestinal failure (corresponding to approximately $75 \%$ of all patients in Denmark $^{7}$ receiving or having initiated HPN during the period November 1995 to March 1997). The other group comprised 76 nonHPN patients with intestinal insufficiency, defined as faecal energy excretion of more than $2.0 \mathrm{MJ} /$ day (measured at a previous admission), a remnant small intestine of $200 \mathrm{~cm}$ or less (measured peroperatively from the ligament of Treitz) or as having undergone consecutive small intestinal resections exceeding $150 \mathrm{~cm}$.

Forty six of the $58 \mathrm{HPN}$ patients and 45 of the 76 non-HPN patients with intestinal insufficiency consented to participate in the study. One of the non-HPN patients was excluded as she experienced gastroenteritis and vomiting during admission. Also, one HPN patient with protein losing enteropathy was excluded as she
Abbreviations used in this paper: $B M R$, basa metabolic rate; HPN, home parenteral nutrition. 
used her catheter for intravenous calcium supplements only. All HPN patients received parenteral supplements of nutrients or saline at least three times a week. Thus the study comprised $45 \mathrm{HPN}$ and 44 non-HPN patients. None of the patients with inflammatory bowel disease showed evidence of active disease.

STUDY PROTOCOL

Patients were admitted for a period of 2.5 days. On arrival on the first afternoon, patients were given three containers and an electronic precision balance (measuring in grams). Two of the containers were designated for collection of faeces and urine, respectively. In the third container, patients were told to collect a duplicate of their oral intake (both liquid and solid foods). When instructed, patients were told that they could eat what they pleased from breakfast, lunch, and supper buffets, each containing a wide range of food items. The beverages available included water, tea, coffee, milk products, soft drinks, juice, glucose-saline solutions, etc. Sandwiches, biscuits, and beverages were available in the kitchen between meals.

Patients were told to abstain from food between 2200 and 0800 on the day of admission so that faecal excretion during the first 24 hours of the study would not be a reflection of intake prior to the balance period. The study and collection period began at 0800 on the second day of admission and patients were requested to urinate, defecate, or empty their stoma bags. During the next 48 hours, patients collected their faeces, urine, and duplicate diets in the three containers. Before admission, intestinal transit was measured by timing a Brilliant Blue marker from oral administration to its appearance in the faeces of non-HPN patients and HPN patients with a preserved colon. These measurements revealed intestinal transit times of less than 10 hours, except in three HPN patients with oral failure and intestinal dysmotility. Thus the limited duration of intestinal transit indicated that 10 hours of fasting between 2200 and 0800 were sufficient so that the events prior to the balance study did not influence the 48 hour balance period. On retrieval, faeces were deposited on ice, immediately frozen, and kept at $-20^{\circ} \mathrm{C}$ until the samples were analysed.

Patients were interviewed about the composition and volume of parenteral support, and information on daily medicine use was obtained. During admission, patients received their usual parenteral supplements and medication. None of the patients was receiving sodium chloride capsules, but patients drinking a glucose-saline solution were told to place a similar portion in their food container. None of the patients required tube feeding (enteral nutrition).

ANALYTICAL METHODS

Patient height and fasting body weight were measured on admission. Body composition was measured during or before admission by dual energy $x$ ray absorptiometry (Norland XR-26 DXA densitometer, Norland Corp., Fort
Atkinson, Wisconsin, USA). In addition, patient weight six months before admission was obtained from weight curves drawn at ambulatory visits. Basal metabolic rate (BMR) was calculated according to the Harris-Benedict equations using actual body weights. ${ }^{8}$

The weight of the 48 hour oral intake was measured together with faecal and urinary losses. Intestinal wet weight absorption was calculated as equivalent to the difference between the weight of the oral intake and faecal weight. Analyses of the diet and faeces were performed on homogenised, freeze dried samples. Dietary and faecal energy contents were determined by bomb calorimetry using approximately $1 \mathrm{~g}$ of freeze dried sample which was combusted in an IKA adiabatic calorimeter (model C 4000 A; IKA-Analysentechnik, Heitersheim, Germany). Intestinal energy absorption was calculated as equivalent to the difference between ingested and excreted energy, and relative absorption as diet-faecal energy/diet energy $\times 100 \%$. The precision of the analytical methods used was demonstrated previously as high, with high reproducibility. ${ }^{9}$ Questionnaires regarding habitual dietary intake of patients were not used. Weight and energy content in parenteral supplements was calculated from information given by the manufacturers. The remnant small intestine was measured peroperatively in 56 patients whereas the length of resection was measured in 31 patients. One of the non-HPN and two of the HPN patients did not have resection of the small intestine. The length of the colon was expressed in terms of percentage of the usual length according to the method of Cummings and colleagues. ${ }^{10}$

ETHICS

The study was approved by the Ethics Committee for Medical Research, Copenhagen, Denmark. The procedures followed were in accordance with the ethical standards of the Helsinki Declaration of 1975, as revised in 1983. All patients gave informed consent before entering the study.

\section{STATISTICAL ANALYSIS}

Results are expressed as median (25-75\% percentiles). Differences between groups were tested using the Mann-Whitney rank sum test and comparisons of frequencies were evaluated by the $\chi^{2}$ test or alternatively by Fisher's exact test using SigmaStat for Windows version 2.0 (copyright 1992-1995, Jandel Corporation, Erkrath, Germany); p $<0.05$ was considered significant.

\section{Results}

PATIENT DEMOGRAPHICS

Patient demographics are shown in table 1 . Most patients had Crohn's disease (37 of 44 in the non-HPN group and 26 of 45 in the HPN group). The two groups had a similar BMR, calculated from the Harris-Benedict equations. Sex and age distributions did not differ between groups. The remnant gut structures of patients are described in table 2 . 
Table 1 Patient demographics

\begin{tabular}{lll}
\hline & $\begin{array}{l}\text { Intestinal insufficiency: } \\
\text { non-HPN }(n=44)\end{array}$ & $\begin{array}{l}\text { Intestinal failure: } \\
H P N(n=45)\end{array}$ \\
\hline Sex (F/M) & $24 / 20$ & $31 / 14$ \\
Diagnosis (CD/MT/surg/RE/ID) & $37 / 3 / 4 / 0 / 0$ & $26 \dagger / 3 / 7 / 3 / 6 \dagger$ \\
Age (years) & $48(43-57)$ & $49(40-57)$ \\
Weight $(\mathrm{kg})$ & $63.2(55.4-70.3)$ & $57.2(50.9-64.5)^{\star}$ \\
Weight $(\mathrm{kg}) 6$ months prior & $62.9(57.0-73.1)$ & $57.9(52.1-65.3)$ \\
Height $(\mathrm{cm})$ & $169(162-177)$ & $166(163-171)$ \\
BMI (kg/m $\left.{ }^{2}\right)$ & $22.1(19.4-24.6)$ & $20.8(18.9-23.2)$ \\
Lean body mass (kg) & $42.7(36.1-50.1)$ & $36.1(32.6-42.2)^{\star}$ \\
Fat mass (kg) & $15.7(9.5-20.4)$ & $19.0(12.4-24.8)$ \\
Bone mass (kg) & $2.8(2.6-3.1)$ & $2.4(2.1-2.8)^{\star \star}$ \\
BMR (MJ/day) & $5.69(5.42-6.91)$ & $5.61(5.32-5.98)$ \\
\hline
\end{tabular}

Results are expressed as median (25-75\% percentiles). CD, Crohn's disease; MT, mesenteric thrombosis; surg, complications related to surgery; RE, radiation enteritis; ID, intestinal dysmotility; BMI, body mass index; BMR, basal metabolic rate according to Harris-Benedict equations. ${ }^{\star} \mathrm{p}<0.05,{ }^{\star \star} \mathrm{p}<0.01$, Mann-Whitney rank sum test.

$t \mathrm{p}<0.05, \chi^{2}$ or alternatively Fisher's exact test.

Table 2 Remaining gut structures

\begin{tabular}{lrrrrr}
\hline & $\begin{array}{c}\text { Intestinal insufficiency: } \\
\text { non-HPN (n=44) }\end{array}$ & $\begin{array}{c}\text { Intestinal failure: } \\
\text { HPN (n=45) }\end{array}$ \\
\hline Time since last resection (years) & \multicolumn{2}{c}{8.6 (5.4-14.7) } & \multicolumn{2}{c}{4.6 (1.9-8.5) } \\
Jejuno/ileostomy & 21 & 27 & \\
Patients with measured remnant intestine (n) & 7 & & 23 & \\
Measured remnant intestine (cm) & 180 & $(165-195)$ & 100 & $(49-140)$ \\
Patients with measured intestinal resection (n) & 14 & & 4 & \\
Measured intestinal resection (cm) & 81 & $(65-100)$ & 90 & $(65-115)$ \\
Patients with remnant ileum (n) & 13 & & 4 & \\
Preserved colon segment & 23 & & 18 & \\
Patients with measured remnant intestine (n) & 15 & & 11 & \\
Measured remnant intestine (cm) & 140 & $(89-158)$ & 90 & $(45-131)$ \\
Patients with measured intestinal resection (n) & 8 & & 7 & \\
Measured intestinal resection (cm) & 108 & $(98-135)$ & 10 & $(0-73)$ \\
Patients with remnant ileum (n) & 7 & & 6 & \\
Preserved ileocecal valve (n) & 7 & & 7 & \\
Remaining colon (\%) & 57 & $(57-100)$ & 64 & $(28-100)$ \\
Remaining rectum-anus (n) & 19 & & 8 &
\end{tabular}

Results are expressed as median (25-75\% percentiles) or number of patients.

Table 3 Energy and dry weight

\begin{tabular}{|c|c|c|}
\hline & $\begin{array}{l}\text { Intestinal insufficiency: } \\
\text { non-HPN }(n=44)\end{array}$ & $\begin{array}{l}\text { Intestinal failure: } \\
\operatorname{HPN}(n=45)\end{array}$ \\
\hline Enteral energy intake (MJ/day) & $11.69(9.28-13.56)$ & $7.56(5.70-9.38)^{\star \star \star}$ \\
\hline Enteral energy intake/BMR (\%) & $178 \quad(161-229)$ & $134 \quad(101-176)^{\star \star \star}$ \\
\hline Enteral energy intake <BMR (n) & 0 & $11++t^{\prime}$ \\
\hline Enteral dry weight intake (kg/day) & $0.55(0.45-0.66)$ & $0.37(0.29-0.47)^{\star \star \star}$ \\
\hline Parenteral energy ( $\mathrm{MJ} /$ day) & - & $3.86(1.70-5.58)$ \\
\hline Parenteral energy/BMR (\%) & - & $72 \quad(33-104)$ \\
\hline Total energy supplies (MJ/day) & $11.69(9.28-13.56)$ & $11.30(9.60-14.09)$ \\
\hline Total energy supplies/BMR (\%) & $178 \quad(161-229)$ & $213 \quad(162-240)$ \\
\hline Faecal energy excretion (MJ/day) & $3.20(2.26-4.73)$ & $4.16(1.28-5.61)$ \\
\hline Faecal energy excretion/BMR (\%) & $54 \quad(40-79)$ & $69 \quad(22-98)$ \\
\hline Faecal dry weight excretion (kg/day) & $0.13(0.10-0.19)$ & $0.17(0.06-0.24)$ \\
\hline Intestinal energy absorption ( $\mathrm{MJ} /$ day) & $7.92(6.54-9.04)$ & $3.96(2.24-5.23)^{\star \star \star}$ \\
\hline Intestinal energy absorption (\%) & $71 \quad(58-78)$ & $49(40-76)^{\star \star}$ \\
\hline Intestinal energy absorption/BMR (\%) & $(114-150)$ & $(40-90)^{\star \star \star}$ \\
\hline Intestinal energy absorption $<\mathrm{BMR}(\mathrm{n})$ & 6 & $36+t+$ \\
\hline Intestinal dry weight absorption ( $\mathrm{kg} / \mathrm{day})$ & $0.40(0.34-0.48)$ & $0.22(0.12-0.28)^{\star \star \star}$ \\
\hline Overall energy balance ( $\mathrm{MJ} /$ day) & $7.92(6.54-9.04)$ & $7.97(6.45-9.03)$ \\
\hline Overall energy balance/BMR (\%) & $1.30(1.14-1.50)$ & $1.41(1.11-1.61)$ \\
\hline
\end{tabular}

Results are expressed as median ( $25-75 \%$ percentiles) or number of patients. BMR, basal metabolic rate according to Harris-Benedict equations.

${ }^{\star \star} \mathrm{p}<0.01,{ }^{\star \star \star} \mathrm{p}<0.001$, Mann-Whitney rank sum test.

$+\dagger+\mathrm{p}<0.001, \chi^{2}$ or alternatively Fisher's exact test.

Table 4 Wet weight absorption

\begin{tabular}{lcc}
\hline & $\begin{array}{l}\text { Intestinal insufficiency: } \\
\text { non-HPN }(n=44)\end{array}$ & $\begin{array}{l}\text { Intestinal failure: } \\
\text { HPN }(n=45)\end{array}$ \\
\hline Enteral intake (kg/day) & $3.56(3.07-4.39)$ & $2.81(2.19-3.70)^{\star \star \star}$ \\
Parenteral nutrition (kg/day) & - & $2.25(1.78-3.16)$ \\
Total supplies (kg/day) & $3.56(3.07-4.39)$ & $5.46(4.37-6.37)^{\star \star \star}$ \\
Faecal excretion (kg/day) & $1.25(0.67-1.83)$ & $2.19(1.17-2.96)^{\star \star}$ \\
Intestinal absorption (kg/day) & $2.48(2.01-2.90)$ & $0.84(-0.01-1.49)^{\star \star \star}$ \\
Intestinal absorption (\%) & $63(55-80)$ & $31(0-51)^{\star \star \star}$ \\
Urine (kg/day) & $1.16(0.94-1.84)$ & $2.23(1.76-3.10)^{\star \star \star}$ \\
Overall balance (kg/day) & $1.13(0.78-1.36)$ & $1.04(0.43-1.57)$ \\
\hline
\end{tabular}

Results are expressed as median (25-75\% percentiles).

${ }^{\star \star} \mathrm{p}<0.01,{ }^{\star \star \star} \mathrm{p}<0.001$, Mann-Whitney rank sum test.
ENERGY

Median dietary energy intake was considerably higher in the non-HPN compared with the HPN patients $(11.69 \mathrm{MJ} /$ day $(\sim 2780 \mathrm{kcal} /$ day $)$ (range 6.71-24.42 $\mathrm{MJ} /$ day) compared with $7.56 \mathrm{MJ} /$ day $(\sim 1800 \mathrm{kcal} /$ day) (range $5.76-$ $21.13 \mathrm{MJ} /$ day); $\mathrm{p}<0.001$ ) (table 3), corresponding to $178 \%$ and $134 \%$ of BMR. In the HPN patients, parenteral support was 3.86 $\mathrm{MJ} /$ day, corresponding to $72 \%$ of $\mathrm{BMR}$, and as a result the energy provided by the diet in the non-HPN patients closely matched the sum of enteral and parenteral nutrition in the HPN patients (11.69 MJ/day (178\% of BMR) and $11.30 \mathrm{MJ} /$ day $(213 \%$ of BMR), respectively; $\mathrm{p}=0.98$ ) (table 3 ). Faecal energy excretion did not differ significantly between the two groups and consequently the abundant intake of the non-HPN patients resulted in intestinal absorption of energy $(7.92 \mathrm{MJ} /$ day, $1885 \mathrm{kcal} /$ day) that was twofold higher than in the HPN patients $(3.96 \mathrm{MJ} /$ day, $940 \mathrm{kcal} /$ day; $\mathrm{p}<0.001)$. Energy absorption as a percentage of BMR was $71 \%$ in the HPN patients and $130 \%$ in the non-HPN patients $(\mathrm{p}<0.001)$. Intestinal absorption, when added to parenteral supplies, resulted in an overall balance of $7.97 \mathrm{MJ} /$ day (141\% of BMR) in the HPN patients, equivalent to intestinally absorbed energy of 7.92 $\mathrm{MJ} /$ day $(130 \%$ of $\mathrm{BMR})$ in the non-HPN group (table 3 ).

\section{WET WEIGHT}

Intestinal wet weight absorption was threefold higher in the non-HPN patients $(2.48 \mathrm{~kg} /$ day $)$ compared with the HPN patients $(0.84 \mathrm{~kg} /$ day; $\mathrm{p}<0.001$ ) (table 4). Oral intakes were 3.56 and $2.81 \mathrm{~kg} /$ day in the non-HPN and HPN patients, respectively. Parenteral fluid supply was $2.25 \mathrm{~kg} /$ day. The overall fluid balance was approximately 1 litre/day in both groups because urine volume in the HPN patients $(2.23 \mathrm{~kg} /$ day $)$ was twice that of the non-HPN patients $(1.16 \mathrm{~kg} /$ day; $\mathrm{p}<0.001)$ (table 4$)$.

SODIUM

Dietary sodium intake was similar in the non-HPN and HPN patients (135 and 134 $\mathrm{mmol} /$ day, respectively; $\mathrm{p}=0.24$ ) (table 5). Parenteral support provided the HPN patients with $177 \mathrm{mmol} /$ day of sodium, resulting in a significantly higher total supply compared with the non-HPN patients (302 $v 135 \mathrm{mmol} /$ day; $\mathrm{p}<0.001)$. Faecal sodium excretion was higher in HPN patients (129 v $105 \mathrm{mmol} /$ day; $\mathrm{p}<0.05$ ) (table 5) whereas intestinal sodium absorption was significantly lower in the HPN patients compared with that found in the nonHPN patients $(-14 v 32 \mathrm{mmol} /$ day; $\mathrm{p}<0.01)$. Urinary sodium excretion was almost fourfold higher in the HPN patients (151 mmol/day) compared with the non-HPN patients (41 $\mathrm{mmol} /$ day; $\mathrm{p}<0.001$ ), and overall sodium balance was positive ( $29 \mathrm{mmol} /$ day) compared with the non-HPN patients $(-31 \mathrm{mmol} /$ day; $\mathrm{p}<0.001$ ) (table 5). 
Table 5 Sodium absorption and excretion

\begin{tabular}{lll}
\hline & $\begin{array}{l}\text { Intestinal insufficiency: } \\
\text { non-HPN }(n=44)\end{array}$ & $\begin{array}{l}\text { Intestinal failure: } \\
\text { HPN }(n=45)\end{array}$ \\
\hline Enteral intake (mmol/day) & $135(104-180)$ & $134(67-159)$ \\
Parenteral nutrition (mmol/day) & - & $177(100-296)$ \\
Total supplies (mmol/day) & $135(104-180)$ & $302(213-434)^{\star \star \star}$ \\
Faecal excretion (mmol/day) & $105(19-159)$ & $129(69-218)^{\star}$ \\
Intestinal absorption (mmol/day) & $32(-18$ to 112$)$ & $-14(-77 \text { to } 39)^{\star \star}$ \\
Intestinal absorption (\%) & $30(-13$ to 89$)$ & $-16(-67 \text { to } 46)^{\star \star}$ \\
Urine (mmol/day) & $41(10-136)$ & $151(59-241)^{\star \star \star}$ \\
Overall balance (mmol/day) & $-31(-58$ to -7$)$ & $29(-30 \text { to } 92)^{\star \star \star}$ \\
\hline
\end{tabular}

Results are expressed as median (25-75\% percentiles).

${ }^{\star} \mathrm{p}<0.05,{ }^{\star \star} \mathrm{p}<0.01,{ }^{\star \star \star} \mathrm{p}<0.001$, Mann-Whitney rank sum test.

THE BORDER BETWEEN INTESTINAL

INSUFFICIENCY AND INTESTINAL FAILURE

The border between intestinal insufficiency in the 44 non-HPN patients and intestinal failure in the 45 patients who received HPN was defined as the $5 \%$ lower confidence interval of energy and wet weight absorption found in the non-HPN patients. This arbitrary confidence interval was found to be reasonable. This definition was based solely on data obtained from non-HPN patients to avoid confounding factors from HPN, which may reduce dietary intake and consequently the amount of energy and wet weight absorbed in patients receiving HPN.

The $5 \%$ lower limit of energy absorption was calculated as equivalent to $84 \%$ of BMR (fig 1 ). The $5 \%$ lower limit of wet weight absorption was $1.41 \mathrm{~kg} /$ day (fig 1). Using the calculated cut off values, fig 1 could be divided into four areas. Patients in the upper right quadrant were those whose intestinal absorption was above the limit (i.e. where HPN was not necessary). Patients located to the left of a wet weight absorption of $1.41 \mathrm{~kg} /$ day were those requiring saline supplements, whereas those with an energy absorption of less than $84 \%$ of BMR required parenteral energy supplements. Patients in the lower left quadrant had a combined need for saline and energy. Thus $5 \%$ of the non-HPN patients had a BMR below $84 \%$ and $5 \%$ were below the $1.41 \mathrm{~kg} /$ day cut off; this was equivalent to four non-HPN patients, of whom three were borderline (fig 1).

Subsequent insertion of the $45 \mathrm{HPN}$ patients into this frame (fig 1) demonstrated that

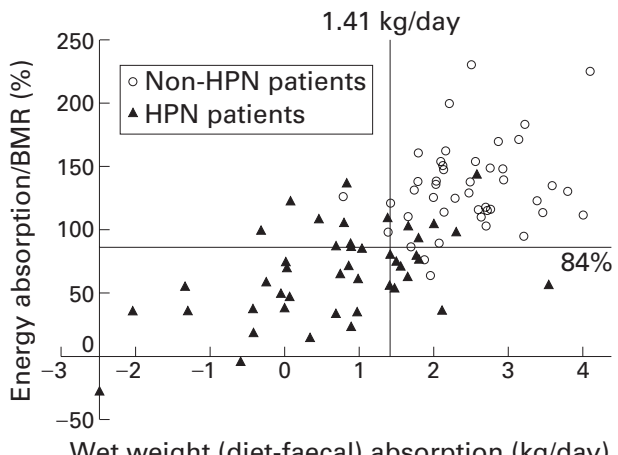

Figure 1 Absorption of wet weight and energy in relation to basal metabolic rate (BMR) calculated by the Harris-Benedict equations in 44 non-HPN patients and in 45 HPN patients. The $5 \%$ confidence limits of the non-HPN patients, defining intestinal failure, are given by the lines. Energy absorption/BMR was $84 \%$ and wet weight absorption $1.41 \mathrm{~kg} /$ day. the borders between intestinal insufficiency and failure defined by the non-HPN patients resulted in a good distinction between nonHPN and HPN patients. Only five HPN patients were located in the upper right quadrant in the area of non-HPN patients.

ORAL INTAKE AND PERCENTAGE ABSORBED

The data presented in fig 1 do not disclose if intestinal failure is due to insufficient absorption of a sufficient amount of food or insufficient intake of food (oral failure). The purpose of figs 2 and 3 was to differentiate between these two different clinical problems, both resulting in intestinal insufficiency or failure.

Figure 2 illustrates the relation between percentage of the diet absorbed (diet-faecal energy/diet energy $\times 100 \%)$ and adequacy of dietary intake (dietary energy as a percentage of BMR). The limits of $84 \%$ of BMR in fig 1 , used to distinguish between intestinal insufficiency and failure, were fitted to the plots from the HPN and non-HPN patients. Several of the HPN patients had an energy intake of less than $84 \%$ of BMR and therefore even $100 \%$ absorption would not help their dependence on $\mathrm{HPN}$ as long as energy intake was that low. Conversely, several of the non-HPN patients

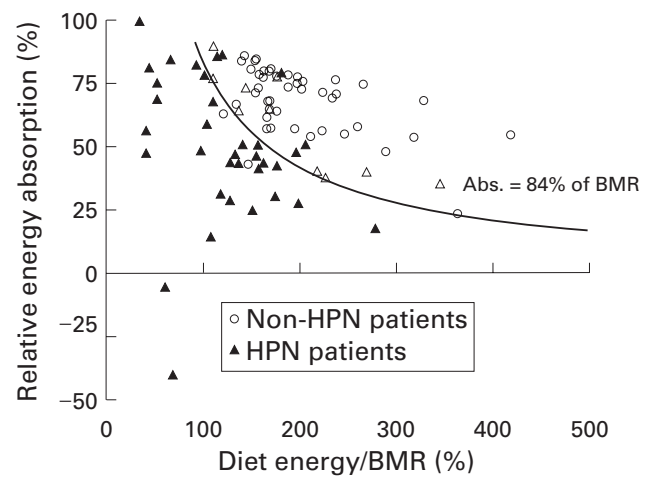

Figure 2 Relative energy absorption in relation to dietary energy intake/basal metabolic rate (BMR) in 44 non-HPN patients and 45 HPN patients. The open triangles indicate HPN patients who received HPN due to a wet weight absorption of less than the $5 \%$ limit $(1.41 \mathrm{~kg} /$ day).

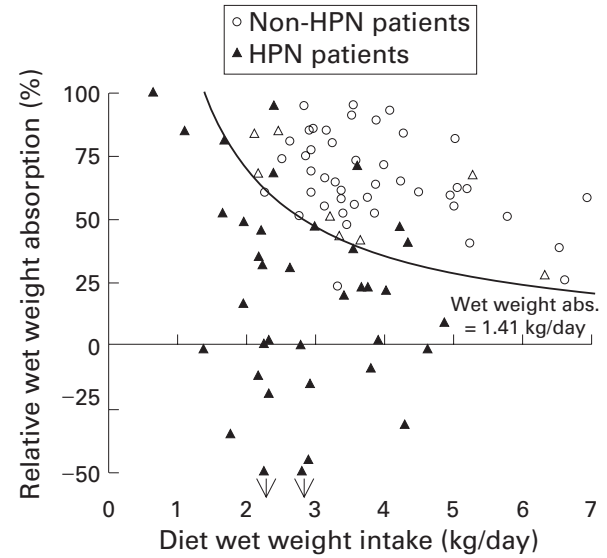

Figure 3 Relative wet weight absorption in relation to the dietary wet weight intake in 44 non-HPN patients and 45 HPN patients. The open triangles indicate HPN patients who received HPN because of energy absorption less than the $5 \%$ limit for basal metabolic rate (BMR) (84\%). 
had compensatory increased energy intake above $200 \%$ of BMR (hyperphagia) which meant that they did not require HPN despite absorption of less than $50 \%$. In fact, one patient had a relative energy absorption (diet-faecal energy/diet energy $\times 100 \%$ ) of only $24 \%$ but consumed $22.18 \mathrm{MJ} /$ day and thus managed to avoid HPN. Fourteen of the HPN patients absorbed more than the limit of $84 \%$ of BMR. However, nine of these patients (indicated by the open triangles in fig 2) had an isolated problem due to wet weight absorption of less than $1.41 \mathrm{~kg} /$ day and did not receive HPN because of insufficient energy absorption. Four of the remaining five patients were borderline and absorbed less than 105\% of their BMR (see below). The last outlying patient received no parenteral energy and less than 1 litre of saline daily.

Figure 3 illustrates the relation between intake of wet weight and percentage absorbed. The limit of $1.41 \mathrm{~kg} /$ day in fig 1 to discriminate between intestinal insufficiency and failure was fitted. Some patients had good absorption above $50 \%$ but an intake of less than 1.5-3 $\mathrm{kg} /$ day, making them dependent on parenteral saline. Other patients who only absorbed $25-50 \%$ did not need parenteral saline as their intakes were 3-7 kg/day. However, as illustrated in fig 1 , the cut off (defined by a final absorption of more than $1.41 \mathrm{~kg} /$ day) was accurate in differentiating between HPN and non-HPN patients over a considerable range of intakes. Thirteen HPN patients absorbed more than the limit of $1.41 \mathrm{~kg} /$ day for wet weight absorption. Eight received HPN to compensate for energy absorption below the upper limit of $84 \%$ of BMR (indicated by the open triangles). The remaining five were the patients described above.

\section{Discussion}

Adequate gut function is needed to maintain intestinal autonomy thus avoiding long term parenteral nutrition. Two principal gut functions are absorption of energy from fat, carbohydrates, and protein sufficient to meet the metabolic needs of the body, and absorption of wet weight and electrolytes, mainly sodium, sufficient to avoid dehydration and electrolyte depletion.

In this study, we invited our total cohort of 58 patient with intestinal failure ${ }^{7}$ (HPN patients, defined as patients in need of HPN at the time of the study) and all of our 76 patients with intestinal insufficiency (non-HPN patients, defined as patients with a short small bowel of less than $200 \mathrm{~cm}$ or considerable malabsorption of at least $2 \mathrm{MJ} / \mathrm{day}$, or both) to participate. A central referral system connecting the small local hospitals throughout Denmark to the intestinal failure unit at the Rigshospitalet ensured referral of patients with the most severe intestinal insufficiency who nevertheless were able to manage without HPN. The non-HPN and HPN patients are described in details in tables 1 and 2. It is important to emphasise that the actual remnant bowel length was disregarded as it was irrelevant to measurements of intestinal func- tion and to the limits defined. Clinicians in charge of patients had no access to the study results and treatment was guided by clinical evaluation of the patients, and by weight, blood tests, and occasional measurements of faecal and urine volumes. In total, $46 \mathrm{HPN}$ patients and 45 non-HPN patients were included.

The main aim of the study was to define the border between intestinal insufficiency and failure using objective measurements of intestinal function (i.e. to identify the minimal level of gut function necessary to avoid long term parenteral support). Intestinal absorption is often measured as a percentage of intake which (as shown in figs 2 and 3) lacks strict clinical bearing because high absorption of an insufficient amount of food still results in intestinal failure.

The border between intestinal insufficiency and failure was a wet weight absorption of $1.41 \mathrm{~kg}$ /day (i.e. patients not able to absorb this quantity would most often need parenteral saline supplements). Most clinicians in charge of these patients would probably agree that 1.5 litres of water seems to be a reasonable minimal amount to compensate for fluids lost from sweat and urine. Because the wet weight absorption includes absorption of approximately $0.40 \mathrm{~kg}$ /day of dry weight, fluid absorption is even less. However, one has to bear in mind the production of water by oxidation of nutrients of approximately $0.03 \mathrm{~kg} / \mathrm{MJ}$, thus accounting for approximately $0.27 \mathrm{~kg} /$ day in the non-HPN patients.

Surprisingly, the calculated 5\% lower confidence level for intestinal sodium absorption was $-85 \mathrm{mmol} /$ day in the non-HPN patients, and their median overall balance was -31 $\mathrm{mmol} /$ day (corresponding to less than $-2 \mathrm{~g}$ /day) (table 5). A plausible explanation of the overall negative sodium balance in the nonHPN patients may be a low degree of patient compliance regarding the addition of salt to the solid food containers.

The border between intestinal insufficiency and failure was $84 \%$ of BMR. At this level, absorption would have to cover BMR and in addition at least $20-30 \%$ to perform daily activities. Even though these patients are known to compensate by low physical activity, it does not explain how they are able to survive at such a low level of energy absorption. Actual BMR was not measured but our data suggest that it was lower in the non-HPN patient closest to the borderline value compared with the estimated BMR calculated by the HarrisBenedict equations. Similar findings have been demonstrated in patients with anorexia nervosa where the resting energy expenditure was reduced to $49-91 \%$ of values predicted by the Harris-Benedict equations. ${ }^{11-13}$

Figure 1 does not demonstrate oral intake and consequently does not discriminate between patients with oral failure (e.g. pseudoobstruction) who may or may not absorb a high percentage of the small amount of food they eat, and short bowel patients, who often absorb a low percentage of a large food intake. Thus to describe the spectrum between these two extremes, the percentage of absorption was 
plotted against dietary intake for energy (fig 2) and wet weight (fig 3).

Figure 2 clearly demonstrates that many of the non-HPN patients were able to compensate by hyperphagia, as previously described. ${ }^{14} 15$ Thirty six percent had an energy intake of $200-419 \%$ of their BMR. Examining fig 2 , it is clear that absorption expressed as a percentage does not help in the classification of a patient before the amount of intake is known, except for those who absorbed less than $25 \%$ of their intake. Patients may absorb up to $100 \%$ but if energy intake is less than $84 \%$ of BMR they will have intestinal failure. Many of these patients had dysmotility disorders combined with pseudo-obstruction. However, if patients who absorb between $100 \%$ and $50 \%$ for example, could eat a minimum of $84-168 \%$ of their calculated BMR, respectively, they may be weaned from HPN and regain intestinal autonomy. Patients with an absorption of $50-25 \%$ would correspondingly have to eat at least $168-336 \%$ of their BMR every day to avoid HPN. The same principles regarding wet weight rather than energy absorption were considered in fig 3. Hence the position of a given patient, non-HPN or HPN, in figs 2 and 3 illustrates the efforts which have to be made by the patient to discontinue or remain on HPN. Patients whose energy or wet weight absorption is less than $25 \%$ are unlikely to be weaned from HPN.

Rodrigues et al investigated energy absorption as a measure of intestinal failure in the short bowel syndrome by bomb calorimetry. ${ }^{6}$ They measured energy absorption from a liquid meal over a six hour period. A median of $87 \%$ (range $82-92 \%$ ) of the energy was absorbed in a group of five patients with ileostomy. Seven short bowel patients not on HPN absorbed $67 \%$ (range 59-78\%), and five short bowel patients receiving HPN absorbed 27\% (range 2-63\%). Messing et al reported a mean coefficient of digestive absorption of energy in five HPN patients of $64 \%$ (range $41-85 \%$ ). ${ }^{16} \mathrm{~A}$ median of $71 \%$ of energy was absorbed by the non-HPN patients in our study (table 3 ) but the range was wide $(24-86 \%$; fig 2$)$. The HPN patients absorbed $49 \%$ of dietary energy (table 3 ), with values ranging from a net loss of energy of $40 \%$ to complete absorption of $100 \%$ (fig 2). Therefore, percentage absorption values obtained in different studies are characterised by a wide range, and thus medians are highly dependent on patient selection.

Nightingale et al focused on wet weight absorption in 15 patients with a short residual length of jejunum and no colon. ${ }^{17}$ In six of the patients who did not require HPN, wet weight absorption was 1.56-2.42 kg/day, closely matching the lower limit in our study. Furthermore, all nine patients who received parenteral supplements were located below the limit suggested.

In summery, patients with intestinal insufficiency who maintained intestinal autonomy and did not depend on parenteral supplements tended to have a wet weight absorption of more than $1.41 \mathrm{~kg} /$ day and an energy absorption exceeding $84 \%$ of their $\mathrm{BMR}$, as calculated by the Harrison-Benedict equations. Patients with intestinal failure, by definition depending on HPN, tended to absorb less of either or both. Preservation of intestinal autonomy was consistent with a large variation in relative intestinal absorption of $25-100 \%$ of either wet weight or energy, as long as oral intake was proportionally increased to meet the total demand, as outlined. Hence the border between intestinal insufficiency and failure was narrow and well defined. Longitudinal studies of the Danish cohort of HPN patients have shown that adaptation occurs in a considerable proportion of patients who are weaned off HPN temporarily or permanently over a period of five years. ${ }^{7}$ Future prospective studies will assess the value of the measurements of energy and wet weight absorption for predicting if patients with intestinal failure will require lifelong HPN. Furthermore, the short term balance tests may become important educational tools for borderline and selected patients in whom weaning from HPN is desired.

We thank Jette Christiansen, Anne Birgitte Larsen and Bodil Petersen for technical assistance.

1 Fleming CR, Remington M. Intestinal failure. In: Hill GL, ed. Nutrition and the surgical patient. New York: Churchill Livingstone, 1981:219-35.

2 Messing B, Hébuterne X. Indications of home artificial nutrition. In: Jonkers CF, ed. Educational book, 19th ESPEN Congress, RAI Amsterdam, The Netherlands, 1997. Amsterdam: The Educational Committee, ESPEN 1997, 1997:114-20.

3 Carbonnel F, Cosnes J, Chevret S, et al. The role of anatomic factors in nutritional autonomy after extensive small bowel resection. F Parenter Enteral Nutr 1996;20:27580 .

4 Gouttebel MC, Saint Aubert B, Astre C, Joyeux H. Total parenteral nutrition needs in different types of short bowel parenteral nutrition needs in different type

5 Nightingale JM, Lennard Jones JE, Gertner DJ, Wood SR, Bartram CI. Colonic preservation reduces the need for parenteral therapy, increases the incidence of renal stones but does not change the high prevalence of gallstones in patients with a short bowel. Gut 1992;33:1493-7.

6 Rodrigues CA, Lennard Jones JE, Thompson DG, Farthing MJ. Energy absorption as a measure of intestinal failure in the short bowel syndrome. Gut 1989;30:176-83.

7 Jeppesen PB, Staun M, Mortensen PB. Adult patients receiving home parenteral nutrition in Denmark from 1991 to 1996: Who will benefit from intestinal transplantation? Scand F Gastroenterol 1998;338:839-46.

8 Schofield WN. Predicting basal metabolic rate, new standards and review of previous work. Hum Nutr Clin Nutr 1985;39 (Suppl 1):5-41.

9 Jeppesen PB. Betydningen af lipidernes fedtsyre-kcedelcengde for deres kliniske effekt $i$ den enterale og parenterale erncering af tarmsyge patienter (Significance of the fatty acid chain length for their clinical effect in the enteral and parenteral length for their clinical effect in the enteral and parenteral nutrition of patients with intestinal disease). Ph

10 Cummings JH, James WP, Wiggins HS. Role of the colon in ileal-resection diarrhoea. Lancet 1973;1:344-7

11 Vaisman N, Rossi MF, Goldberg E, Dibden LJ, Wykes LJ, Pencharz PB. Energy expenditure and body composition in patients with anorexia nervosa. F Pediatr 1988;113:919-24.

12 Schebendach JE, Golden NH, Jacobson MS, Hertz S, Shenker IR. The metabolic responses to starvation and refeeding in adolescents with anorexia nervosa. Ann NY Acad Sci 1997;817:110-19.

13 Krahn DD, Rock C, Dechert RE, Nairn KK, Hasse SA. Changes in resting energy expenditure and body composition in anorexia nervosa patients during refeeding. $\mathcal{F} \mathrm{Am}$ Diet Assoc 1993;93:434-8.

14 DiCecco S, Nelson J, Burnes J, Fleming CR. Nutritional intake of gut failure patients on home parenteral nutrition. intake of gut failure patients on home pare

15 Cosnes J, Lamy P, Beaugerie L, Le Quintrec M, Gendre JP, Le Quintrec Y. Adaptive hyperphagia in patients with postsurgical malabsorption. Gastroenterology 1990;99:1814-19.

16 Messing B, Pigot F, Rongier M, Morin MC, Ndeindoum U, Rambaud JC. Intestinal absorption of free oral hyperalimentation in the very short bowel syndrome. Gastroenterology 1991;100:1502-8.

7 Nightingale JM, Lennard Jones JE, Walker ER, Farthing MJ. Jejunal efflux in short bowel syndrome. Lancet 1990;336: $765-8$. 


\section{LETTERS TO THE EDITOR}

Differential expression of cyclooxygenase 2 in human colorectal cancer

EdiToR,-We were puzzled by the recent paper by Dimberg and colleagues (Gut 1999;45:730-732) which reported that upregulation of cyclooxygenase $2(\mathrm{COX}-2)$ protein expression was prominent in rectal adenocarcinomas compared with that in adenocarcinomas arising from the colon. "Low or undetectable levels of COX-2 protein expression" were demonstrated in 15 of 19 colonic adenocarcinomas located proximal to the rectum. Overall, upregulation of COX-2 protein expression was reported in only $56 \%$ of colorectal cancers.

Previous reports, ${ }^{1-7}$ which include one by the current authors on a not dissimilar case series ${ }^{1}$ and two in the joint authorship of the accompanying commentary writer, ${ }^{23}$ have shown consistent upregulation of COX-2 expression in colonic and rectal adenocarcinomas (in $85-90 \%$ of cases) compared with matched normal colonic mucosa using different techniques, including northern blot analysis, RT-PCR, western blot analysis, and immunohistochemistry. Furthermore, four of these studies refer to the distribution of adenocarcinomas throughout the colon without showing evidence of differential COX-2 expression between rectal and more proximal tumours. ${ }^{1245}$ In the one previous study which analysed COX-2 protein expression in human colorectal cancers by western blot analysis, ${ }^{7}$ immunoreactive COX-2 was detected in $76 \%$ of cases with a 10 -fold increase in median tissue COX-2 concentration compared with normal colonic mucosa.

In our view, the authors should attempt to explain the discrepancy between their results and previously published data. It is interesting to note that, in the study of Kargman et al, five of six patients taking NSAIDs had low or undetectable COX-2 protein expression. Moreover, aspirin has recently been shown to suppress induction of COX-2 mRNA and protein in interleukin- $1 \beta$ and phorbol ester stimulated human endothelial cells and fibroblasts. ${ }^{8}$ Do the authors have data on NSAID use in their cohort of patients prior to surgery?

M HULL

Division of Medicine and Molecular Medicine Unit, University of Leeds, Leeds, UK Email:medmah@stjames.leeds.ac.uk

M LANGMAN

University of Birmingham, Birmingham, UK

1 Dimberg J, Samuelsson A, Hugander A, et al. Gene expression of cyclooxygenase-2, group I and cytosolic phospholipase A2 in human colorectal cancer. Anticancer Res 1998;18:3283-7.

2 Eberhart CE, Coffey RJ, Radhika A, et al. Up-regulation of cyclooxygenase 2 gene expression in human colorectal adenomas and adenocarcinomas. Gastroenterology 1994;107:1183-8.

3 Shattuck-Brandt RL, Lamps LW, Heppner Goss KJ, et al. Differential expression of matrilysin and cyclooxygenase- 2 in intestinal and colorectal neoplasms. Mol Carcinog 1999;24: 177-87.

4 Gustafson-Svard C, Lilja I, Hallbook O, et al. Cyclooxygenase- 1 and cyclooxygenase- 2 gene expression in human colorectal adenocarcinomas and in azoxymethane induced coloni tumours in rats. Gut 1996;38:79-84.
5 Maekawa M, Sugano K, Sano H, et al. Increased expression of cyclooxygenase- 2 to -1 in human colorectal cancers and adenomas, but not in hyperplastic polyps. Jpn f Clin Oncol 1998;28: 421-6.

6 Sano H, Kawahito Y, Wilder RL, et al. Expression of cyclooxygenase-1 and -2 in human colorectal cancer. Cancer Res 1995;55: 3785-9.

7 Kargman SL, O'Neill GP, Vickers PJ, et al. Expression of prostaglandin $\mathrm{G} / \mathrm{H}$ synthase-1 and -2 protein in human colon cancer. Cancer Res 1995;55:2556-9.

8 Xu X-M, Sansores-Garcia L, Chen X-M, et al. Suppression of inducible cyclooxygenase 2 gene transcription by aspirin and sodium salicylate. Proc Natl Acad Sci USA 1999;96: 5292-7.

\section{Reply}

EdiToR,-We agree with Drs Hull and Langman that we found upregulation of COX-2 protein expression in a lower fraction of colorectal cancers (CRC) than previously reported. In part, this may simply be explained by the composition of different tumour types within $\mathrm{CRC}$ - that is, the number of colonic versus rectal tumours in our cohort compared with others. In the papers referred to it is difficult to assess the fraction of the different tumour types studied. The differences may also be dependent on the genetic basis for the CRCs studied, which we also have indicated in our report but perhaps not emphasised sufficiently. CRCs with a defective mismatch repair capability, recognised by microsatellite instability (MSI), are accompanied by reduced COX-2 levels. ${ }^{1}$ At present, we do not know the fraction of MSI type tumours in our series and therefore cannot assess this possibility. An indirect estimate may be achieved since the Min mouse model and human studies provide direct evidence that COX-2 expression may be related to loss of APC function. ${ }^{2}$ APC and $\beta$-catenin mutation analysis of our tumour series shows a good, although not perfect, correlation with COX-2 protein upregulation. Among 18/20 rectal tumours with COX-2 protein upregulation, 12 contained mutations in the APC/ $\beta$ catenin genes. In contrast, only one of three $\mathrm{APC} / \beta$-catenin mutated colon tumours revealed COX-2 protein induction and among the remaining 15 non-mutated tumours, two displayed COX-2 protein upregulation. Thus the fraction of $\mathrm{APC} / \beta$-catenin mutated tumours was also slightly lower (21/38-55\%) than previously reported and in accordance with the differential COX-2 induction observed. This may indicate that a larger fraction of CRCs in our cohort are of the MSI type.

Other possibilities for the differences in the fraction of COX-2 upregulation in our tumour series may be the definition of "induction". In our case, a tumour/normal ratio from densitometric scanning of western blots must exceed 2 in two successive independent experiments of the same sample pair to be considered true induction. The use of different methodologies may also influence relative expression of $\mathrm{COX}-2$, for example RT-PCR is sensitive to the quality of isolated mRNA and PCR is not really a quantitative method but needs to be carefully controlled to allow quantitative estimations.

It is also correct, as stated by Drs Hull and Langman, that NSAIDs may suppress COX-2 mRNA induction and COX-2 protein expression in some of the patients in our series. Normally, all drug treatments are withdrawn at least one week prior to surgery at our hospital, making most patients drug free at the time of surgery. However, we do not know if patients self-administer these types of drugs during the waiting period. We have reviewed the medical records for all CRCs included in the study and found that $7 / 39$ patients were receiving aspirin for cardiovascular protection. Five of these patients had rectal tumours and displayed 7-40-fold induction of COX-2 protein: the two patients with colonic cancer and aspirin treatment revealed $<2$ - and 10 -fold induction, respectively. Thus COX-2 suppression caused by NSAID cannot explain the low prevalence of COX-2 induction in the colonic tumours.

Regulation of COX-2 is not fully understood. Because of the close correlation of upregulated COX-2 with mutations in APC/ $\beta$-catenin genes it has been hypothesised that there is a regulatory link and that the chemopreventive effect of NSAIDs can be attributed to inhibition of COX-2. However, in a recent paper by $\mathrm{He}$ and colleagues ${ }^{3}$ it was demonstrated that PPAR $\delta$ (peroxisome proliferator activated receptor $\delta$ ) is a target of both APC and NSAIDs resulting in suppressed PPAR $\delta$ activity and promotion of apoptosis. In addition, COX-2 null mouse embryo fibroblast cells remain sensitive to the antiproliferative and antineoplastic effects of NSAIDs $^{4}$; hence there seems to be other important mechanisms for NSAID mediated tumour suppression.

The samples in our series were obtained consecutively without any selection. At present, we believe that the observed differential expression of COX-2 may be due to underlying differences in genetic alterations and/or that rectal tumours may represent a biologically distinct subtype of bowel cancer. However, we cannot exclude the possibility that the next 39 CRCs collected will display the opposite COX-2 expression pattern, although we believe this is unlikely.

J DIMBERG Department of Natural Science and Biomedicine, University College of Surgery, Faculty of Health Sciences, fönköping, Sweden Email:dija@hhj.hj.se P SÖDERKVIST Department of Biomedicine and Division of Cell Biology, Faculty of Health Sciences, Linköping, Sweden Email:petso@mcb.liu.se

1 Karnes WE, Shattuck-Brandt R, Burgart LJ, et al. Reduced COX-2 protein in colorectal cancer with defective mismatch repair. Cancer Res 1998;58:5473-7.

2 Oshima M, Dinchuk JE, Kargman SL, et al. Suppression of intestinal polyposis in $\mathrm{Apc}^{716}$ knockout mice by inhibition of cyclooxygenase 2 (COX-2). Cell 1996;87:803-9.

$3 \mathrm{He}$ TC, Chan TA, Vogelstein B, et al. PPAR $\delta$ is an APC-regulated target of nonsteroidal antian APC-regulated target of nonsteroidal

4 Zhang X, Morham SG, Langenbach R, et al. Malignant transformation and antineoplastic actions of nonsteroidal anti-inflammatory drugs (NSAIDs) on cyclooxygenase-null embryo fibroblasts. F Exp Med 1999;190:451-60.

\section{Proton pump inhibitors for Barrett's} oesophagus

Editor,- - Recently, the authors of two leading articles, Triadafilopoulos (Gut 2000; 46:144-46) and Shepherd (Gut $2000 ; 46: 147-49)$ referred to our paper in Gut. ${ }^{1}$ We would like to draw attention to the fact that the legend in tables 4 and 5 in our paper should be read as (cm.month), (squares.month), and (\%.month) since the variable is the area under the curve (AUC), which is the product of length or surface and 
time. The printed notation (with a slash) might suggest that the figures concern the change per month. In spite of our suggested change in the galley proof, this notation was maintained. Nevertheless, it does not change the purport of our conclusion, nor the discussion in both leading articles.

F T M PETERS

Department of Gastroenterology and Hepatology, Groningen University Hospital, PO Box 30 001, 9700 RB Groningen, The Netherland Email:ftm.peters@int.azg.nl

1 Peters FTM, Ganesh S, Kuipers EJ, et al. Endoscopic regression of Barrett's oesophagus double blind study. Gut 1999;45:489-494.

\section{MCP-3 in inflammatory bowel disease}

EDITOR,-We read with interest the article by Wedemeyer and colleagues (Gut 1999; 44:629-35) on chemokines in inflammatory bowel disease.

Monocyte chemotactic protein 3 (MCP-3) expression in inflammatory bowel diseases is a very interesting observation and we agree with the authors that MCP-3 might play an important role in the pathophysiology of these diseases.

We have recently published an article on the C-X-C chemokines interleukin (IL)-8 and IP-10, and the C-C chemokines MCP-1 and MCP-3 in the mucosa of active ulcerative colitis. ${ }^{1}$ It concerns an immunohistochemica study in which we showed increased expression of these chemokines in the lamina propria of patients with ulcerative colitis compared with normal controls. Furthermore, we observed a significant difference in expression between inactive and moderate/ severe ulcerative colitis based on the histological grading in MCP-1, MCP-3, and IL-8.

Wedemeyer and colleagues state in their discussion that MCP-1 is expressed in the epithelial cells and lamina propria whereas MCP-3 is almost exclusively produced by epithelial cells. However, in the results section and further in the discussion the authors mentioned sporadic MCP-3 expression in the lamina propria of inflamed tissue. The photographs show only epithelial cells and it is not possible to see the staining pattern of the lamina propria.

We found MCP-3 expressing cells in the lamina propria which was significantly increased in active ulcerative colitis compared with both inactive ulcerative colitis and normal controls. Furthermore, MCP-3 expression in lamina propria was also enhanced in patients suffering from pouchitis compared with patients with a normal pouch (unpublished data).

In the study of Wedemeyer et al, unfortunately the data on MCP-3 expression in Crohn's disease were not significant which might be because of the small number of patients examined. It would be interesting to further evaluate the role of chemokines in Crohn's disease.

In conclusion, albeit with some minor differences, both studies have shown that MCP-3 plays an important role in ulcerative colitis.

U HELWIG K M LAMMERS P GIONCHETTI

F RIZZELLO

$M$ CAMPIERI

Department of Internal Medicine and Gastroenterology, University of Bologna, Bologna, Italy Email:paolo@meol.unibo.it
M UGUCCIONI Theodor Kocher Institute, University of Bern, Bern, Switzerland

1 Uguccioni M, Gionchetti P, Robbiani DF, et al. Increased expression of IP-10, IL-8, MCP-1 and MCP-3 in ulcerative colitis. Am $\mathcal{F}$ Pathol 1999;155:331-6.

\section{Reply}

Editor,-We thank Dr Helwig and colleagues for their interest in our recent paper in which we showed enhanced expression of the C-C chemokine MCP-3 in inflammatory bowel disease mucosa. In the article by Uguccioni and colleagues, ${ }^{1}$ we noted their slightly different findings in terms of localisation of MCP-3 expression. Using different techniques (cryostat and paraformaldehyde fixatives, different anti-MCP-3 antibodies) we found consistent expression of MCP-3 in the intestinal epithelium and sporadically in the lamina propria. Uguccioni et al reported MCP-3 expression in the lamina propria. The reason why they did not find MCP-3 expression in the epithelium remains unclear. A possible explanation could be that patients received different therapies at the time of colonoscopy. Only one of the patients investigated in the study by Uguccioni et al received steroids while most patients with macroscopic inflamed mucosa enrolled in our study received either oral or parenteral steroid medication at the time of biopsy. As mentioned in the results, we also found occasional MCP-3 staining cells within the lamina propria but did not focus our investigation on these cells. Which lamina propria cells express MCP-3 remains to be determined. We found that human isolated mast cells are capable of expressing MCP-3 mRNA (unpublished data) which makes them a possible candidate. Other candidates are macrophages and endothelial cells, as reported by Ying and colleagues, ${ }^{2}$ who found MCP-3 expression in bronchial biopsies located in these two cell types and in epithelial cells.

In conclusion, we agree with Dr Helwig and colleagues that the role of chemokines in inflammatory bowel disease needs to be evaluated in more detail. Further data are necessary to answer the question of whether or not these alterations in chemokine expression are restricted to specific disorders such as ulcerative colitis or resemble a more general finding associated with any type of intestinal inflammation and host defence mechanisms.

J WEDEMEYER A LORENTZ M P MANNS $S \mathrm{C}$ BISCHOFF

Department of Gastroenterology and Hepatology, Medical School of Hannover, Hannover, Germany Email: bischoff.stephan@mh-hannover.de

1 Uguccioni M, Gionchetti P, Robbiani DF, et al. Increased expression of IP-10, IL-8, MCP-1
and MCP-3 in ulcerative colitis. Am $\mathcal{f}$ Pathol and MCP-3 in ulce

2 Ying S, Meng Q, Zeibecoglou K, et al. Eosinophil chemotactic chemokines (eotaxin, eotaxin-2, RANTES, monocyte chemoattractant protein-3 (MCP-3), and MCP-4), and C-C chemokine receptor 3 expression in bronchial biopsies from atopic and nonatopic (intrinsic) asthmatics. F Immunol 1999;163:6321-9.

One minute unbuffered urease test: should it be read at 10 minutes?

EDITOR,- - The one minute unbuffered rapid urease test, ${ }^{1}$ previously described in your journal, ${ }^{2}$ was adopted for use at the Royal Melbourne Hospital endoscopy day ward because of its affordability, ease of use, and rapidity. Over time, we had noticed a number of cases where the test had been negative at the one minute mark but later became positive. As we were unsure of whether these "late" positive results represented true or false positives, we decided to run a short study to assess the accuracy of the urease test compared with the "gold standard" of histology.

To this end we read and recorded the urease test at one and 10 minutes and compared the results with histological demonstration of Helicobacter pylori on a single antral biopsy. This was carried out on 90 unselected patients undergoing upper gastrointestinal endoscopy for varied indications. Forty one patients were found to have $H$ pylori on histology. The urease test was positive in 20 of these 41 when read at one minute compared with 34 at 10 minutes. There were two false positive results at the one minute mark and four at the 10 minute mark. The performance of the urease test at one and 10 minutes is compared in table 1 .

We have demonstrated a significant disparity from published data ${ }^{2}$ in the sensitivity of the ultra rapid urease test in our ward. Previous reports have shown a difference between the test results at one minute compared with 15 minutes but this was attributed to the lower initial temperature of the test solution as it was kept refrigerated until just prior to use. ${ }^{3}$ In our ward the test solution is made up in batches and stored at $4^{\circ} \mathrm{C}$ in the refrigerator but the test tubes are put out at the beginning of the day and thus start off at room temperature. There is evidence to suggest that storage at $4^{\circ} \mathrm{C}$ for a number of days has no deleterious effects on the performance of the rapid urease test $^{3}$ but this factor may explain the poor performance of the one minute test in our hands.

These factors aside, it is important to point out that we have concluded that the rapid urease test is quite accurate, with sensitivity and specificity comparable with published values $^{4-6}$ for other urease tests, if the reading time is modified to 10 minutes. There are other instances ${ }^{3}{ }^{4}$ of variability of urease test performance depending on the time interval at which it is read. It may be that, prior to use, these tests need to be validated as conditions may vary from the prescribed ones under which the test was designed.

At 10 minutes the unbuffered urease test still provides results quicker than most rapid urease tests and in fact allows us to inform patients and organise further management for them prior to discharge from the endoscopy suite. Given the overall performance of the test, we are quite happy to plan the treatment of $H$ pylori on the basis of its results. Histology can be reserved for those cases where urease testing is equivocal or other signs, such as mucosal abnormalities, are being sought.

S SENGUPTA G CROSTHWAITE University Department of Surgery, Royal Melbourne Hospital, Parkville 3050, Australia

Table 1 Comparison of the unbuffered rapid urease test performance at one and 10 minutes

\begin{tabular}{lllc}
\hline & $\begin{array}{l}1 \text { min } \\
\text { test }\end{array}$ & $\begin{array}{l}10 \text { min } \\
\text { test }\end{array}$ & p Value \\
\hline Sensitivity & $49 \%$ & $83 \%$ & $<0.001$ \\
Specificity & $96 \%$ & $92 \%$ & 0.20 \\
Positive predictive value & $91 \%$ & $90 \%$ & 0.43 \\
Negative predictive value & $69 \%$ & $87 \%$ & $<0.002$ \\
\hline
\end{tabular}


Correspondence to: G Crosthwaite, 1st Floor, 55 Flemington Rd, North Melbourne 3051, Australia. Email: g.1.crosthwaite@bigpond.com

1 Arvind AS, Cook RS, Tabaqchali S, Farthing MJG. One-minute endoscopy room test fo Campylobacter pylori. Lancet 1988;i:704.

2 Thillainayagam AV, Arvind AS, Cook RS, Harrison IG, Tabaqchali S, Farthing MJG. Diagnostic efficiency of an ultrarapid endoscopy room test for H pylori. Gut 1990;32:467-9.

3 NG FH, Wong SY, NG WF. Storage temperature of the unbuffered rapid urease test. $A m \mathcal{F}$ Gastroenterol 1997;92:2230-1.

4 Yousfi MM, El-Zimaity HM, Cole RA, Genta RM, Graham DY. Comparison of agar gel (CLOtest) or reagent strip (PyloriTek) rapid urease tests for detection of (PyloriTek) rapid Am f Gastroenterol 1997:92:997-9.

5 Cutler AF. Testing for H. pylori in clinical pracCutler AF. Testing for H. pylori in
tice. Am $\mathcal{f}$ Med 1996;100:35-41S.

6 tice. Am 7 Med 1996;100:35-41S. Weston AP, Campbell DR, Hassanein RS,
Cherian R, Dixon A, McGregor DH. Prospective, multivariate evaluation of CLOtest performance. Am $\mathcal{F}$ Gastroenterol 1997;92:1310-15.

\section{Thalidomide treatment of oesophageal ulceration}

EDITOR,-I read with interest the case report of oesophageal ulceration treated successfully with thalidomide (Gut 1999;45:463-464). With others, I reported the first successful use of this drug in oesophageal ulceration in $1992^{1}$ although the patient we reported on did indeed have AIDS, and the ulceration was diffuse and proliferative rather than discrete, mimicking lymphoma both macroscopically and microscopically.

The precise mechanism of thalidomide's effectiveness in oesophageal ulceration remains unclear. The case reported raises the intriguing possibility of more widespread application of this drug in idiopathic gastrointestinal ulceration. It has already been used in the lower gastrointestinal tract in Crohn's disease with some success. Idiopathic aphthous ulceration may be the first step in the pathogenesis of Crohn's disease-the breach in the mucosal barrier may allow entry of bacterial flora and their products to the internal milieu thus setting in train the inflammatory cascade that becomes clinical inflammatory bowel disease. A potent, orally available, and especially non-teratogenic $\mathrm{T}$ cell inhibitor as effective as thalidomide would be a useful addition to the pharmacological weaponry available for use in inflammatory bowel disease and perhaps also in helicobacter negative gastroduodenal and small intestinal ulceration.

J RYAN

Brighton Gastroenterology Associates, Suite 5, 2 Church St, Brighton 3186, Victoria, Australia

Email:jeremy@brightongastro.com

1 Ryan J, Colman J, Pedersen J, Benson E. Thalidomide to treat esophageal ulcer in AIDS. New Engl f Med 1992;327:208.

\section{Use of Doppler ultrasound in Crohn's disease}

EDITOR,-We read with interest the article by Maconi et al (Gut 1998;43:654-650). We find it encouraging that other workers are interested in superior mesenteric artery (SMA) flow concerning Crohn's disease activity. Our group has been working on the subject for several years. However, we found it surprising to read that "according to the literature" SMA flow does not correlate with disease activity. Firstly, disease activity needs to be defined. The Crohn's disease activity index does not correlate with disease activity in individual patients ${ }^{12}$ and the reference standard used by Maconi et al is probably not a reliable indicator for disease activity. Secondly, it is not correct in our view to correlate the resistive index in one article ${ }^{3}$ with mean velocity in another ${ }^{4}$ and flow volume in yet another, ${ }^{56}$ and make the statement "yielding conflicting results" on page 654 . In our opinion only flow volume measurements can be used as a reliable indicator. ${ }^{58}$ The fact that Maconi et al did not find a correlation between SMA volume flow and disease activity is probably caused by their choice of reference standard, as pointed out by Kjeldsen and colleagues, ${ }^{1}$ Hodgson and Bhatti, ${ }^{2}$ and van Oostayen and colleagues. ${ }^{5}$

J A VAN OOSTAYEN M N J M WASSER Leiden University Medical Centre, Department of Diagnostic Radiology, Bldg I, C2-S, Albinusdreef 2, 2333 ZA, Leiden, Netherlands

1 Kjeldsen J, Schaffalitzky de Muckadell OB. Assessment of disease severity and activity in inflammatory bowel disease. Scand f Gastroen terol 1993;28:1-9.

2 Hodgson HJF, Bhatti M. Assessment of disease activity in ulcerative colitis and Crohn's disactivity in ulcerative colitis and Crohn'

3 Bolondi L, Gaiani S, Brignola C, et al. Changes in splanchnic hemodynamics in inflammatory bowel disease. Non-invasive assessment by Doppler ultrasound flowmetry. Scand $\mathcal{F}$ Gastroenterol 1992;27:501-7.

4 Maconi G, Imbesi V, Bianchi Porro G. Doppler ultrasound measurement of intestinal blood flow in inflammatoty bowel disease. Scand $\mathcal{F}$ Gastroenterol 1996;31:950-3.

5 Van Oostayen JA, Wasser MNJM, Griffioen G et al. Doppler sonography evaluation of superior mesenteric artery flow to assess Crohn's disease activity: correlation with clinical evaluation, Crohn's disease activity index, and $\alpha_{1}$-antitrypsin clearance in feces $A f R$, $m$ ( Roentgenol 1997;168:429-33.

6 Hare C, Hassan MT, Bartram CI, et al. Superior mesenteric artery Doppler flow: a valuable mesenteric artery Doppler flow: a valuable
indicator of disease activity in Crohn's disease. Gut 1996:38:A639 (abstract).

7 Van Oostayen JA, Wasser MNJM, Van Hogezand RA, Griffioen G, De Roos A. Activity of zand RA, Griffioen G, De Roos A. Activity of
Crohn disease assessed by measurement of Crohn disease assessed by measurement of superior mesenteric artery flow
US. Radiology 1994;193:551-4.

8 Van Oostayen JA, Wasser MNJM, Griffioen G, Van Hogezand RA, C.B.H.W.L, De Roos A Diagnosis of Crohn's ileitis and monitoring of disease activity: value of Doppler ultrasound of superior mesenteric artery flow. Am $\mathcal{F}$ Gastroenterol 1998;93:88-91.

Percutaneous drainage of echinococcal cysts (PAIR-puncture, aspiration, injection, reaspiration): results of a worldwide survey for assessment of its safety and efficacy

EDITOR,-In 1996 a letter (Gut 1996;38:936) about the use of PAIR (puncture, aspiration, injection of a scolecidal agent, reaspiration) raised a criticism of Dr Morris, a leading expert on the treatment of echinococcosis. ${ }^{1}$
At the same time the WHO Informal Working Group on Echinococcosis launched a survey to evaluate the status of this procedure. A number of centres around the world known to be active in this field were requested to complete forms for patients treated with PAIR: 765 abdominal cysts, mostly hepatic, treated with this technique were reported from various countries. We report the results of this survey (table 1 ).

Either needles (18-22 gauge) or catheters (5-9 French gauge), depending on the size and location of the cysts, were used. Scolecidal agents were mainly $20 \%$ hypertonic saline and $95 \%$ ethanol solution. After aspiration and parasitological control of the fluid, a quantity of scolecidal agent, approximately equivalent to one third of the amount aspirated, was injected into the cysts and left for a time varying from 5 to 30 minutes, and then reaspirated: only in the cases of Giorgio and colleagues ${ }^{2}$ was the scolecidal agent not reaspirated. In all cases, except for two failures $(0.26 \%)$ followed by surgery, various degrees of reduction in size (at least $50 \%$ ) and involution (healing) of the cysts were observed on ultrasound follow up. Anaphylactic shock occurred in four cases $(0.52 \%)$ and was promptly treated; in one case $(0.13 \%)$ death ensued notwithstanding resuscitative manoeuvres. Recurrences were observed in 12 cases $(1.57 \%)$ but in eight $(1.05 \%)$ they were related to an insufficient amount of scolecidal agent (one tenth instead of the average equivalent of one third of the aspirated fluid). Spillage of the fluid in the abdominal cavity was observed in four cases $(0.52 \%)$ but all patients were receiving prophylaxis with albendazole (seven days to four hours before to 1-4 weeks after) and no peritoneal dissemination occurred. Minor complications (fever, rash, abscess formation, and biliary fistules) were observed in 105 cases $(13.7 \%)$; abscess formation was treated with echo guided percutaneous drainage. The follow up is more than five years for 75 cases at the time of presentation of this survey.

These data show that the use of PAIR is widespread and increasing, especially in countries where echinococcosis is endemic. This is also because of its low cost and high efficacy. These data are in accordance with the literature: as of today more than 2400 cysts have been punctured and reported in indexed journals, and success and complication rates are even lower than those of our survey. PAIR is a safe and effective therapeutic tool; the risk of anaphylaxis during PAIR has been greatly overrated. Complication rates, recurrences, and mortality rates are lower than those of surgery. ${ }^{3}$ Accuracy of follow up may be a problem where the population is nomadic, but so far no case of peritoneal dissemination after PAIR has been reported.

Table 1 Results of the survey on PAIR by the WHO Informal Working Group on Echinococcosis

Total cases (cysts)
Follow up $>5$ y
Follow up $<5$ y
Major complications
Anaphylactic shock
Spillage
Minor complications
Fever (33), rash (14), pain (30), infection of
cavity (11), nausea and vomiting (10), intracystic
haemorrhage (3), hypotension (2)
Failures
Recurrences

765

75
690

$4(0.52 \%)$ (1 death- $0.13 \%)$

$4(0.52 \%)$ (albendazole prophylaxis)

$105(13.7 \%)$

$2(0.26 \%)$

$12(1.57 \%)(8(1.05 \%)$ due to an insufficient quantity of scolicide) 
There is a need for further studies on PAIR. One of the main issues is to standardise at least some of the points of the various PAIR protocols, under the supervision of the WHO, to compare their efficacy, set up prospective studies, and distribute guidelines to optimise the use of the treatment. Whereas before we felt that the technique was limited to a narrow group of patients, ${ }^{4}$ today we believe that PAIR is not only an alternative but an effective first choice diagnostic and therapeutic tool in the management of human cystic echinococcosis.

C FİLICE

E BRUNETTI

R BRUNO

WHO-INFORMAL WORKING GROUP ON ECHINOCOCCOSIS-PAIR NETWORK† Divisione di Malattie Infettive e Tropicali, IRCCS Policlinico S Matteo, Università di Pavia, via Taramelli 5, 27100, Pavia, Italy

Correspondence to: E Brunetti.

Email:selim@unipv.it

†D Vuitton, Besançon, France; P Schantz, Atlanta, USA; M Caremani, Arezzo, Italy; A Giorgio, Napoli, Italy; C Bastid, Marseille, France; J Napaniak, Poznan, Poland; E Zeyhle, Nairobi, Stefaniak, Poznan, Poland; E Zeyhle, Nairobi,
Kenya; H Wen, China; V Pelaez, Neuquèn, Kenya; H Wen, China; V Pelaez, Neuquen, Argentina; R Pettinari, Chubut, Argentina;
Akhan, Ankara, Turkey; S Men, Ankara, Turkey; G Hernandez, Avila, Spain; H Schipper, Amsterdam, Netherlands.

1 Morris DL. Percutaneous aspiration in the treatment of hydatid liver cysts. Gut 1996;38:936.

2 Giorgio A, Tarantino L, Francica G, et al. Unilocular hydatid liver cysts: treatment with US-guided, double percutaneous aspiration and alcohol injection. Radiology 1992;184:70510.

3 Khuroo MS, Wani NA, Javid G, et al. Percutaneous drainage compared with surgery for hepatic hydatid cysts. $N$ Engl f Med 1997;337: 881-7.

4 Filice C, Brunetti E. Echo-guided diagnosis and treatment of hepatic hydatid cysts. Clin Infect Dis 1997;25:169-71.

\section{Reply}

EDITOR,-I remain unconvinced of two basic things: is it (PAIR) safe and is it effective? With regard to safety these are three issues.

(a) Anaphylaxis. This occurred in four patients after PAIR in the current report and caused one death. An additional three patients became hypotensive and 14 developed a rash. I believe this is a higher risk than surgery should entail.

(b) Dissemination. The peritoneal dissemination of hydatid disease due to needling a liver cyst will take some time to present-how long? In a series of patients with peritoneal hydatid disease, presentation did not occur until nine years (5-14 years) after surgery. ${ }^{1}$ Current follow up of PAIR does not address this issue. Spillage of hydatid material only causes recurrence in approximately $30 \%$ of patients. ${ }^{2}$ Peritoneal hydatid can be a serious or fatal problem.

(c) Sclerosing cholangitis. A significant proportion of hydatid cysts communicate with the biliary tree; use of scolicidal agents even at open surgery has caused sclerosing cholangitis. The surgeon has the opportunity of identifying and protecting such a communication prior to the use of scolicide.

Is it effective? The comment that the recurrence rate of PAIR is now less than sur- gery is either simplistic or deliberately misleading. Filice et al state that 75 patients (or is it cysts?) have been followed up for five years-the type and frequency of follow up is not stated and this is really critical. Careful ultrasonic follow up can demonstrate recurrence following surgery in up to $22 \%$ of patients ${ }^{3}$ but one can equally well quote surgical series with poor follow up with low recurrence rates; to claim that recurrence rates are lower following PAIR when the type and completeness of follow up is not even stated in scientifically quite invalid.

That cysts shrink (variably) following PAIR is reported, but what does this mean - is this synonymous with parasite death? I doubt it! Only one PAIR study reported reaspiration at three days post-PAIR ${ }^{4}$ and $2 / 14$ patients had live proloscolices.

The use of albendazole for four hours to seven days prior to and for 1-4 weeks after PAIR is clearly an attempt to reduce the risk of recurrence. In my original laboratory work it took of the order of 30 days to be effective ${ }^{5}$ and in humans, two patients who received albendazole for one and three weeks, respectively, prior to operation had viable proloscolices. $^{6}$ The use of post-spillage therapy to reduce the risk of implantation has been variably effective in animal models of spillage. $^{78}$

We have made at least some attempt to define the minimum length of such therapy. ${ }^{8}$

The over representation of a poor presentation of data, which I suspect is of even poorer quality, does not improve my view of PAIR, or of the WHO working group. I am quite prepared to accept that PAIR may be the best available option in some areas of the world where surgery and perioperative care are compromised by economic factors or lack of experience, but its comparison with surgery should await careful long term follow up. Department of Surgery St George Hospital, University of New South Wales, Kogarah 2217, Australia

Correspondence to: Professor D Morris.

Email: David.Morris@unsw.edu.au

1 Koravias DD, Vagianos CE, Kakkos SK, Panagopoulos CM, Andrcula K. Peritonal echinococcosis. World f Surg 1996;20:337-40.

2 Schiller CF. Complications of echinococcus cyst rapture. A study of 30 cases. $\mathcal{F A M A} 1966 ; 195$ : 220-2.

3 Little JM, Hollands MT, Eckberg H. Recurrence of hydatid disease. World F Surg 1988;12: 700-4.

4 Giorgio A, Tarantino L, Francica G, et al. Unilocular hydatid liver cysts: treatment with US-guided, double percutaneous aspiration and alcohol injection. Radiology 1992;184:70510 .

5 Chinnery JB, Morris DL. Effect of albendazole sulphoxide on viability of hydatid protosceleces in vitro. Trans $R$ Soc Trop Med Hyg 1986;80: 815-17.

6 Morris DL. Preoperative albendazole therapy in hydatid cyst. Br F Surg 1987;74:805-6

7 Morris DL, Chinnery J, Hardcastle JD. Can albendazole reduce the risk of implantation of spilled protoscoleces? An animal study. Trans $R$ Soc Trop Med Hyg 1986;80:481-4.

8 Taylor DH, Morris DL, Richards KS. Perioperative prophylactic chemotherapy of echinococcus granulosus: Determination of minimucciniin vitro protoscolex culture. HPB Surgery in vitro protoscolex culture. HPB Surgery
$1990 ; 2: 159-64$.
BOOK REVIEWS

Mucosal T cells. Chemical Immunology. Vol 71. Edited by MacDonald TT. (Pp 242; illustrated; individuals $\$ 104.50$, institutions \$208.75.) Switzerland: Karger, 1998. ISBN 3805567227 .

I should say immediately that this is an excellent book. For those interested in mucosal immunology, little more is necessary. It comprises an up to date and comprehensive series of 13 reviews by scientists who have made important contributions to the field. I am very pleased to have a copy; it will be extremely useful.

Clinical gastroenterologists spend a great deal of their time battling with mucosal $\mathrm{T}$ cells, yet because these cells are too small to be seen with an endoscope (in any case they would be obscured in exudate or by the epithelial cell layer) and are difficult to stain on formalin fixed histopathology sections, they are rarely observed. The weapons used against these adversaries are principally nonspecific drugs which have, obviously, worked if the patient gets better.

Thus, although it is tempting to take Sherlock Holmes' attitude and, when told by Watson that the earth revolves around the sun, feel that the mind is an attic that when filled with details of astronomy (or mucosal immunology), will leave no space for the more useful minutiae of Egyptian tobacco (or the indications for the latest biliary expanding metal stent). But Holmes liked to have a comprehensive grasp of the background of the case, and I believe that he would not have missed a chance to study this book had he been a contemporary gastroenterologist.

The language of the book may be a problem for the non-immunologist, particularly if one's medical school notes stop at the Bursa of Fabricius. This is certainly state of the art immunology, but is directed at clinicians as well as scientists. Therefore, if you want to know more about current developments in inflammatory bowel disease, coeliac disease, or HIV, or you are just curious about what some of those cells that you see in biopsy samples might be doing, I strongly recommend that you invest some money in a copy of this book and some effort in reading it. Furthermore, I suggest beginning with the chapter on "Mouse models of gut inflammation"-such models may not be identical to human inflammatory bowel disease, but at least they give us an opportunity to understand it.

And if you can't remember what CD25 is? Get a copy of Immunobiology by Janeway and Travers (3rd Edition; Current Biology Ltd, 1997); this is another excellent book where no previous knowledge is assumed. There you are - two rave reviews-or three if you count $A$ Study in Scarlet.

A J S MACPHERSON

Gastrointestinal Endosonography. Edited by Van Dam J, Sivak MV. (Pp 298; illustrated; £95.00.) UK: W B Saunders \& Company, 1999. ISBN 0721679897.

This is a collection of work by 31 predominantly North American, European, and Japanese gastroenterologists, digestive surgeons, 
and radiologists. The list of authors includes leading figures in the field of digestive endosonography, namely those who took part in the development of the first pieces of equipment and who described the basic principles of endoscopic ultrasound, and the new generation of practitioners responsible for the most recent developments in this area, particularly the introduction of the endoscopic ultrasound guided puncture. This collective work is complete and exhaustive: it is in large format and divided into seven sections, supplemented by a very detailed and helpful index.

The book is a popular work and the teaching material it contains is very practical, detailed, and useful for beginners. However, the book relies on the experiences of the expert authors, which I find to be of much less interest. Much of their experience is now outdated and there is little scope for discussion of other practices. It contains few illustrations of variable quality. I find it strange that colour Doppler and endoscopic images are grouped at the beginning of the book and reproduced in black and white in appropriate chapters.

In summary, this is a book of high quality work with some good illustrations. The division between the technical sections and those on anatomy is well balanced, which is original to this type of work and is very informative. A number of chapters are extremely useful, particularly those on the linear array echoendoscope and portal hypertension. Some areas covered have less impact, particularly those concerned with the authors' different experiences of gastrooesophageal and retroperitoneal pathology. Generally, retroperitoneal endosonography is poorly covered; biliary echoendoscopy is not discussed at all. This significant gap is an invitation to other authors to publish a work dedicated to biliopancreatic echoendoscopy; a useful supplement to the work of doctors van Dam and Sivak.

L PALAZZO

An Atlas of Diagnostic Radiology in Gastroenterology. Edited by Vallance $R$. (Pp 396; illustrated; $£ 120$ ) Oxford: Blackwell Science, 1998. ISBN 0632050225.

It seems almost unimaginable to me that, somewhere out there, exists a clinical gastroenterologist who would not want to own this book. Maybe I was destined to be the curator of the book review section of Gut just so that a review copy of this majestic atlas might come across my desk. What little effort it is to find words of praise for this tour de force of gastrointestinal radiology.

In one of the most delightfully understated introductions of the century, Roddy MacSween writes that "...this volume brings credit to radiology as a discipline". Oh yes indeed, and so very much more! Dr Vallance and selected colleagues have produced a book in which every single illustration (and there are many hundreds) is crystal clear. There are many radiological texts that are comprehensive, and there is a lesser number in which the pictures are clear. There are few books indeed in which every picture credibly reveals the pathology in a totally convincing manner. I do not believe there is single illustration in this book that is not of a high order, and this applies equally to plain radiographs, barium studies, ultrasound, CT, MRI, angiography, or EUS.

Despite its visual excellence, there are idiosyncrasies. Quite what CT and MRI scans of parotid tumours are doing in a book of GI radiology quite escapes this reviewer. Less satisfactory still are some of the mini essays introducing each system. I suspect most readers will not be particularly enlightened by the two page essays that introduce each organ - too brief to say any more than most clinicians must surely know already. For example, who would learn much from:

Ileostomy enema. The distal small bowel may be examined satisfactorily in patients with an ileostomy by retrograde infusion of barium with or without air, introduced by Foley catheter.

The essays are weak, but the legends and the figures are of exceptional quality. A well constructed legend obviates the need for arrows, or other marks, on the radiograph. In this atlas, arrows do appear from time to time, but they are not intrusive. I suggest that this atlas might very well be added to the extremely short list of books that every gastroenterologist should own.

IAN FORGACS

\section{NOTES}

Sir Frances Avery Jones British Society of Gastroenterology Research Award 2001

Applications are invited by the Education Committee of the British Society of Gastroenterology who will recommend to Council the recipient of the 2001 Award. Applications (TWENTY COPIES) should include:

- A manuscript (2 A4 pages ONLY) describing the work conducted

- A bibliography of relevant personal publications

- An outline of the proposed content of the lecture, including title

- A written statement confirming that all or a substantial part of the work has been personally conducted in the UK or Eire.

Entrants must be 40 years old or less on 31 December 2000 but need not be a member of the Society. The recipient will be required to deliver a 30 minute lecture at the Annual meeting of the Society in Glasgow in March 2001. Applications (TWENTY COPIES) should be made to the Honorary Secretary, British Society of Gastroenterology, $3 \mathrm{St}$ Andrews Place, London NW1 4LB by 1 December 2000.

\section{British Society of Gastroenterology Hopkins Endoscopy Prize 2001}

Applications are invited by the Endoscopy Committee of the British Society of Gastroenterology who will recommend to the Council the recipient of the 2001 Award. Applications (TEN COPIES) should include:

- A manuscript (2 A4 pages ONLY) describing the work conducted

- A bibliography of relevant personal publications

- An outline of the proposed content of the lecture, including title

- A written statement confirming that all or a substantial part of the work has been personally conducted in the UK or Eire.

An applicant need not be a member of the Society. The recipient will be required to deliver a 20 minute lecture at the Annual meeting of the Society in Glasgow in March 2001. Applications (TEN COPIES) should be made to the Endoscopy Section Secretary, British Society of Gastroenterology, $3 \mathrm{St}$ Andrews Place, London NW1 4LB by 1 December 2000.

\section{CORRECTIONS}

An error occurred in the paper by Fisher et al (Gut 2000;46:534-539). Levels of protein C, protein S, antithrombin and factor VII were tenfold too high throughout the manuscript. In the Methods section, normal ranges for protein $\mathrm{C}$, protein $\mathrm{S}$, antithrombin and factor VII should have read 66-122 U/dl, 68-146 $\mathrm{U} / \mathrm{dl}, 75-140 \mathrm{U} / \mathrm{dl}$, and 50-150 U/dl. Similar corrections should apply throughout the Results section and in the legend to figure 1 . This was an editorial error for which Gut apologises.

An error occurred in figure 1 in the paper by Jeppesen and Mortensen (Gut 2000;46:701706). The correct figure is published below. The correct figure appears on the Gut website (www.gutinl.com) and thus diverges from the print version of the May issue. We apologise for any confusion this error may have caused.

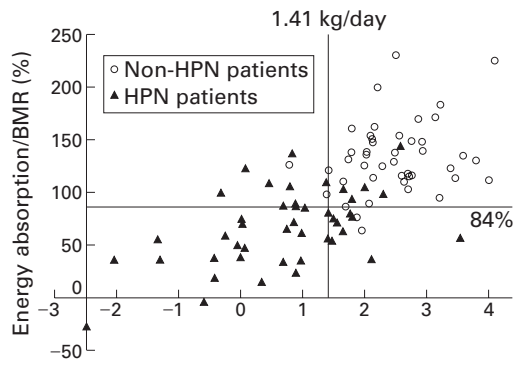

Wet weight (diet-faecal) absorption (kg/day)

Figure 148 hour balance studies defining intestinal failure. Absorption of wet weight and energy in relation to the basal metabolic rate (BMR) calculated by the Harris-Benedict equations in 44 patients managing without parenteral support (non-HPN patients, open circles) and in 45 patients depending on home parenteral nutrition (black triangles). The 5\% confidence limits of the non-HPN patients, defining intestinal failure, are given by the lines. Energy absorption/BMR was $84 \%$ and wet weight absorption $1.41 \mathrm{~kg} /$ day. 